\title{
KARTU PERKALIAN SENILAI SEBAGAI ALTERNATIF METODE PEMBELAJARAN PERKALIAN PADA SISWA SD
}

\author{
Dwi Erna Novianti, Ari Indriani, Dian Ratna Puspananda
}

Pendidikan Matematika, FPMIPA, IKIP PGRI Bojonegoro

\begin{abstract}
Abstrak
Mutu dan kualitas pendidikan ditentukan oleh banyak faktor. Salah satu faktor yang penting untuk meningatkan mutu dan kualitas tersebut adalah proses pembelajaran. Proses pembelajaran ini meliputi situasi, lingkungan belajar, pihak yang terlibat dalam pembelajaran dan media pembelajaran yang digunakan. Kartu Perkalian Senilai ini merupakan salah satu media pembelajaran yang didesain sesuai dengan tujuan dalam meningkatkan kemampuan perkalian di antaranya: (a) meningkatkan kemampuan perkalian pada siswa Sekolah Dasar (SD melalui media pembelajaran, (b) memberikan referensi bagi guru maupun sekolah terkait media pembelajaran inovatif untuk diaplikasikan di dalam proses pembelajaran. Permainan Kartu Perkalian Senilai ini digunakan untuk menguatkan konsep perkalian siswa. Siswa dapat menggunakan kartu perkalian senilai ini secara berkelompok dan dalam permainan berkelompok tersebut, siswa menggunakan konsep perkalian yang sudah didapat sebelumnya. Respon siswa terhadap permainan kartu senilai ini diperoleh dengan metode wawancara. Berdasarkan hasil wawancara tentang pelaksanaan kegiatan ini, diperoleh hasil yaitu peningkatan kemampuan siswa dalam perkalian dan motivasi siswa dalam belajar matematika karena pembelajarannya dilakukan dengan permainan. Selain itu, bagi guru (tutor), kegiatan ini dapat menambah pengetahuan tentang metode pembelajaran matematika khususnya materi perkalian, dan dengan menggunakan media tersebut, tutor dan siswa mampu berkreasi untuk mengembangkan maupun menciptakan media inovatif lainnya yang merangsang motivasi belajar anak untuk terus meningkat.
\end{abstract}

Keywords: Kartu Perkalian Senilai, Permainan.

\section{Abstract}

The quality of education is determined by many factors. One important factor for keeping in mind the quality and quality is the learning process. This Learning Process includes a discussion of the Environment, learning involved and the learning media used. Value Multiplication Card is one of the learning media that is designed in accordance with the objectives in increasing multiplication ability: (a) increasing multiplication ability in Elementary School students through learning media, (b) providing a reference for teachers This Value Multiplication Card Game is used to strengthen the concept Based on the results of this activity, Students can use this value multiplication card in groups and in the group game, students use the concept of multiplication that has been obtained previously. Student responses to this worth of card games were obtained by the interview method. Based on interview about the implementation of this activity, the results obtained are increased student ability in multiplication and student motivation in learning mathematics because learning is done with games. Thus, for teachers (tutors), this activity can increase knowledge about specific mathematics learning methods for multiplication material, and by using these media, it is expected that tutors and students are able to be creative to develop or create other innovative media that encourage children's learning motivation to continue to increase.

Keywords: Value Multiplication Card, Game.

Correspondence author: Dwi Erna Novianti, E-mail, Bojonegoro, Indonesia

This work is licensed under a $C C-B Y-N C$ 


\section{PENDAHULUAN}

Tujuan pendidikan nasional yang tercantum dalam Undang-Undang Nomor 20 tahun 2003 (pasal 3) adalah mengembangkan potensi peserta didik agar menjadi manusia yang beriman dan bertakwa kepada Tuhan Yang Maha Esa, berakhlak mulia, sehat, berilmu, cakap, kreatif, mandiri, dan menjadi warga negara yang demokratis serta bertanggung jawab. Tujuan ini mengisyaratkan bahwa pendidikan memegang peranan penting dalam proses pengembangan kemampuan peserta didik dalam hal kecakapan, kreatifitas dan kemandirian. Menurut (Nurdin, 2016), selain membutuhkan pemgetahuan secara akademik, siswa juga membutuhkan bekal keterampilan yang relevan dengan lingkungan kehidupannya agar dapat langsung bekerja sesuai dengan keterampilan yang dimilikinya selama mengikuti pendidikan. Hal tersebut merupakan bagian penting yang tidak terpisahkan dari proses pembelajaran baik pembelajaran secara formal maupun pembelajaran informal.

Proses pembelajaran yang dilaksanakan secara efektif, terarah, lancar dan sesuai dengan tujuan pembelajaran dapat menentukan terwujudnya mutu pendidikan. Salain itu terdapat juga faktor - faktor lain yang akan mempengaruhi proses pembelajaran itu apakah dapat berlajan lancar dan efektif. (Anugraheni, 2017) menjelaskan, faktor tersebut dapat berasal dari peserta didik itu sendiri, guru, fasilitas, lingkungan belajar dan media pembelajaran yang digunakan. Siswa yang aktif dan kreatif didukung fasilitas serta guru yang menguasai materi dan strategi penyampaian yang efektif akan semakin menambah kualitas pembelajaran.

Salah satu sarana untuk meningkatkan mutu pembelajaran adalah penggunaan media dalam proses pembelajaran. Penggunaan media dapat memotivasi siswa untuk belajar secara mandiri dan kreatif, serta dapat mengurangi kejenuhan siswa. Menurut (Suriyah, 2018) proses pembelajaran dengan menggunakan media pembelajaran juga merupakan salah satu strategi memusatkan pembelajaran pada siswa atau Student Centered Learning (SCL).

Seperti yang kita ketahui, usia anak- anak merupakan usia yang identik dengan permainan. Anak - anak dapat mengenal konsep hanya dengan bermain. Dengan bermain anak akan lebih mudah menerima konsep-konsep tersebut daripada diajarkan seperti orang dewasa yang sedang belajar (NailiRohmah, 2016). Belajar tentunya akan menjadi suatu ritunitas yang membosankan untuk anak - anak jika dilakukan dengan kaku, menegangkan, bahkan jika dikemas dengan suasana yang terlalu serius. Terlebih lagi jika hal tersebut diperapkan dalam pelajaran Matematika. Guru dituntut lebih kreatif dalam membuat inovasi - inovasi baru dalam pembelajaran, yaitu inovasi yang menggabungkan antara permainan dan pembelajaran sehingga dapat meningkatkan ketertarikan siswa dalam belajar matematika. Salah satu alternatif yang bisa digunakan guru adalah pembelajaran dengan media "Kartu Perkalian Senilai" untuk pembelajaran perkalian pada siswa SD kelas II. Pengenalan media pembelajaran ini dilakukan dalam kegiatan Pengabdian Kepada Masyarakat (PKM) yang dilakukan oleh dosen Prodi Pendidikan Matematika di Bimbingan Belajar "Gugusan Bintang" untuk siswa kelas II SD. Permainan dengan media kartu ini bertujuan untuk memantapkan konsep perkalian yang sudah didapatkan siswa sehingga dapat meningkatkan kemampuan siswa dalam perkalian. Bimbingan belajar "Gugusan Bintang" yag berada di bawah naungan Yayasan Kampung Ilmu Bojonegoro (YKIB) merupakan bimbingan belajar yang terletak di kecamatan Purwosari, Bojonegoro. Bimbingan belajar ini memiliki sekitar 140 siswa mulai dari siswa tingkat SD sampai tingkat SMA. 
Berdasarkan uraian di atas, maka penting dilakukan suatu kegiatan kegiatan Pengabdian Kepada Masyarakat (PKM) dengan memanfaatkan media pembelajaran inovatif, dalam hal ini adalah terkait "Kartu Perkalian Senilai" di Bimbel "Gugusan Bintang" yang terletak di desa Purwosari, Kecamatan Purwosari, Kabupaten Bojonegoro.

\section{METODE PELAKSANAAN}

Pemanfaatan media dalam kegiatan ini bertujuan untuk meningkatkan pemahaman konsep perkalian pada siswa. Kartu yang digunakan berisi tentang perkalian, kemudian siswa mencari bentuk perkalian lain yang senilai. Melalui media ini juga siswa akan mampu memahami perkalian dengan konsep, tidak hanya dengan hafalan, karena perkalian merupakan materi dasar yang digunakan untuk materi matematika yang lebih lanjut.

Kegiatan Pengabdian Kepada Masyarakat (PKM) ini dilakukan selama 2 hari yaitu pada tanggal 1 - 2 Nopember 2019, bertempat di Bimbingan belajar "Gugusan Bintang" Yayasan Kampung Ilmu Bojonegoro (YKIB). Bimbel ini beralamatkan di Desa Purwosari RT 03/ RW 05 Kecamatan Purwosari, Kabupaten Bojonegoro. Bimbel ini dipilih sebagai tempat PKM karena berdasarkan hasil observasi dan informasi, memiliki jumlah isiswa yang banyak dan antusias siswa untuk belajar di daerah tersebut sangat tinggi.

Tim PKM terdiri dari 3 dosen dari Prodi Pendidikan Matematika. Hari pertama tim melakukan pembekalan dan sosialisasi tentang media pembelajaran secara umum dan media pembelajaran yang akan digunakan serta melakukan review materi perkalian. Untuk hari kedua, tim mempraktikkan secara langsung media pembelajaran yang berupa kartu perkalian senilai. Setelah itu siswa diminta untuk mempratikkan bersama kelompoknya, dibawah arahan dan bimbingan dari tim.

\section{Alur Kegiatan}

1. Persiapan

Beberapa kegiatan yang akan dilakukan pada tahap persiapan yaitu :

a. Melakukan observasi dengan pihak terkait dalam hal ini dengan pengelola Bimbel dan pimpinan Yayasan Kmpung Ilmu Bojonegoro (YKIB).

Tahap observasi dilakukan dengan melakukan wawancara oleh tim dengan pihak pengelaola bimbingan belajar untuk mengetahui apakah sudah ada media pembelajaran yang bervariatif dalam ragka proses pembelajaran pada bimbingan belajar tersebut. Berdasarkan wawancara tersebut diperoleh nformasi bahwa pembelajaran yang dilakukan selama ini menggunakan metode latihan soal (drill). Informasi ini yang selanjutnya digunakan sebagai acuan untuk mengembangan media pembelajaran yang inovatif untuk siswa agar pembelajaran lebih bervariatif.

b. Pembuatan proposal dan penyelesaian administrasi untuk program pengabdian masyarakat.

c. Penyiapan alat dan bahan untuk pembuatan permainan kreatif yaitu "Kartu Perkalian Senilai".

Tim PKM melakukan persiapan dengan menyiapkan alat - alat yang diperlukan untuk membuat media yang diperlukan yaitu media kartu perkalian dan meyiapkan soal - soal perkalian yang digunakan. Soal perkalian ini dibagi 
menjadi 2 level, yaitu level 1 untuk perkalian angka 1sampai dengan5, sedangkan soal untuk yang level 2 adalah perkalian angka 6 sampai dengan 10. Pembuatan level ini bertujuan untuk memperudah siswa dalam menggunakan media kartu ini.

2. Pelaksanaan kegiatan

Kegiatan pengabdian kepada masayarakat akan dilaksanakan setelah semua pada tahap persiapan sudah selesai dilakukan. Kegiatan akan dilaksanakan di Bimbngan Belajar "Gugusan Bintang" di bawah naungan Yayasan Kampung Ilmu Bojonegoro (YKIB). Pada tahap pelaksanaa kegiatan PKM ini, pemateri memberikan intruksi atau arahan bagaimana cara mengaplikasikan media pembelajaran "Kartu Pecahan Senilai" ini kepada siswa sasaran. Setelah itu, siswa diminta untuk mencoba sendiri media ini dengan berkelompok.

3. Evaluasi

Pada tahap evaluasi ini bertujuan untuk melihat perkembangan program yang dilaksanakan, untuk mengetahui kendala apa saja yang terjadi selama pelaksanaan kegiatan PKM berlangsung, dan solusinya sehingga program pengabdian yang dilaksanakan benar-benar dapat mencapai hasil yang efektif, maksimal sesuai dengan yang diinginkan.

Pada akhir kegiatan dilakukan evaluasi dengan melakukan wawancara dengan siswa dan pengelola bimbel. Salah satu anggota tim PKM (Pengabdian Kepada Masyarakat) dari dosen melakukan wawancara saat menggunakan media pembelajaran "Kartu Perkalian Senilai" secara berkelompok. Pedoman wawancara berisi hal-hal yang berkaitan dengan kegiatan PKM.

4. Pembuatan Laporan

a. Pembuatan Laporan Awal

Pembuatan laporan awal disesuaikan dengan hasil yang telah dicapai selama melakukan pelatihan dengan judul "Kartu Perkalian Senilai Sebagai Alternatif Pembelajaran Perkalian Pada Siswa Kelas II SD”

b. Revisi Laporan

Melakukan revisi laporan dengan tujuan apabila terjadi kesalahan pada pembuatan laporan awal.

c. Pembuatan Laporan Akhir

Pembuatan laporan akhir dilakukan setelah melakukan revisi pada laporan awal agar dalam penyusunan laporan akhir diperoleh hasil yang lebih baik.

Berikut adalah bagan alur tahapan pelaksanaan PKM.

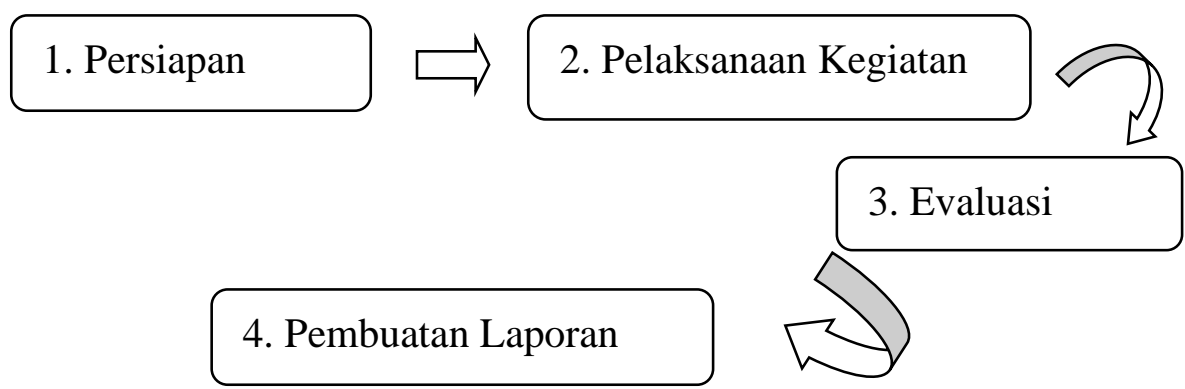

Gambar 1 Diagram Alur Tahapan Pelaksanaan Program 


\section{HASIL DAN PEMBAHASAN}

Kegiatan Pengabdian Kepada Masyarakat (PKM) dengan menggunakan media Kartu Perkaian Senilai ini diikuti oleh siswa kelas II, III dan IV Sekolah Dasar. Peserta adalah siswa yang mengikuti bimbingan belajar di bimbingan belajar tersebut. Peserta yang berjumlah 40 anak sangat bersemangat dan antusias dalam mengikuti kegiatan ini. Hal ini terlihat dari semangat mereka dari awal kegiatan sampai akhir kegiatan yang terlihat sangat tertarik mengikuti kegiatan ini. Mereka mengikuti dan memperhatikan penjelasan dari tim PKM dengan seksama.

Materi tentang perkalian diberikan pada awal kegiatan untuk mereview kemampuan perkalian peserta. Pemateri adalah ketua tim PKM dari dosen dari Prodi Pendidikan Matematika IKIP PGRI Bojonegoro yang terdiri dari 3 dosen dan 1 mahaiswa. Anggota yang lainnya mendampingi peserta pada saat menggunakan media Kartu Perkalian Senilai. Tim dosen memberikan contoh cara melakukan permainan dengan media kartu ini, kemudian mendampingi peserta untuk mempratikkan secara berkelompok.

Pengabdian Kepada Masyarakat (PKM) yang dilaksanakan selama dua hari ini berjalan sesuai dengan apa yang direncanakan dan diharapkan. Pada hari pertama dilakukan persiapan dan pemberian materi tentang media pembelajaran inovatif yang sering dipakai pada pembelajaran matematika secara umum kepada pihak pengelola bimbel dan tutor yang ada di bimbel tersebut. Peserta pada hari pertama pelaksanaan terlihat sangat antusias dan tertarik dalam mengikuti kegiatan ini. Pada hari kedua tim PKM memberikan materi dan contoh cara menggunakan media kartu perkalian senilai. Tim terlebih dahulu menjelaskan aturan bermain dan memberikan contoh cara memainkan permainan kartu ini secara berkelompok. Setelah peserta paham, peserta diminta untuk mempratikkan sendiri dengan didampingi oleh tim PKM. Peserta merasa penasaran karena permainan dengan kartu perkalian ini merupakan hal yang baru bagi mereka. Mereka bermain dalam kelompok masing - masing sesuai dengan aturan permainan yang ada dan secara bergantian bermain dengan kartu level 1 dan level 2.

Pada akhir kegiatan dilakukan wawancara dengan beberapa siswa yang dipilih secara acak untuk evaluasi kegiatan PKM ini. Wawancara dilakukan secara langsung dengan pedoman wawancara yang sudah dibuat. Berikut adalah contoh pedoman wawancara yang digunakan oleh Tim.

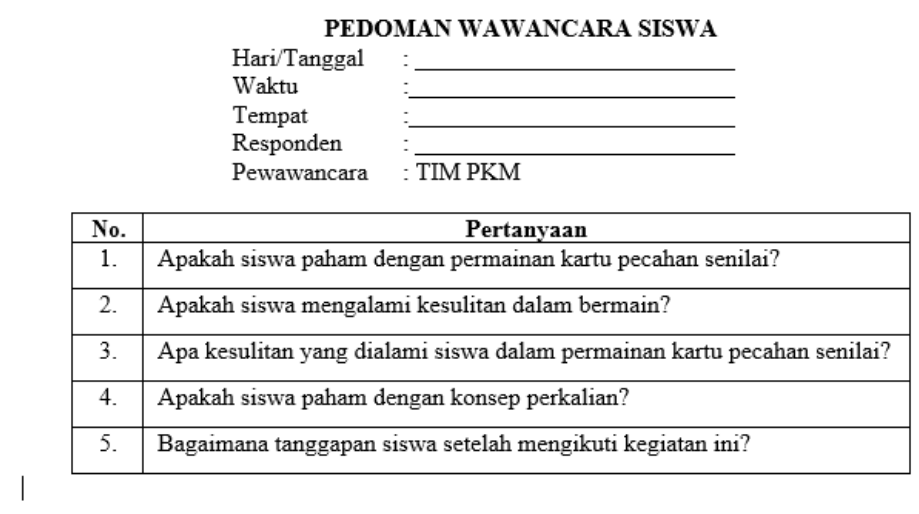

Gambar 2 Pedoman Wawancara 
Berikut adalah penggalan wawancara antara tim (T) dengan siswa perempuan (SP) dan Tim (T) dengan siswa laki - laki (SL).

\section{Wawancara 1}

T : 'Selamat sore dik, dengan adik Najwa ya..'

SP : 'Selamat Sore Kak'

T : 'adik tadi sudah bermain kartu perkalian ya...bagaimana permainannya?'

SP : 'iya sudah kak...awalnya tadi agak bingung ini permainannya gimana...'

$\mathrm{T} \quad$ : 'owh tadi sempat bingung ya, bingung dibagian mana dik...?'

SP : 'iya kak..tapi setelah dijelaskan lagi akhirnya tau dan bisa...'

$\mathrm{T}$ : 'bagaimana permainannya menurut adik..?'

SP : 'bagus kak..kita seperti main kartu tetapi isinya perkalian, trus kita juga harus hafal juga perkaliannya biar bisa pasang - pasangkan...'

T : 'owh begitu, adik senang dengan permainan katru ini..?'

SP : 'senang kak...karena sambil main...'

$\mathrm{T}$ : 'terima kasih dik...'

\section{Wawancara 2}

T : 'Selamat sore dik, dengan Rio ya..'

SL : 'iya kak...Selamat Sore...'

T : 'adik tadi sudah bermain kartu perkalian ya...bagaimana permainannya?'

SL : 'iya sudah kak... permainanya asyik kak'

T : 'tadi langsung bisa atau bagaimana?'

SL : 'iya kak..langsung bisa, karena aku sudah bisa perkalian...'

T : 'bagaimana permainannya menurut adik..?'

SL : 'asyik kak..seperti mengingat perkalian tetapi dipakai di permainan kartu...'

T : 'owh begitu, adik senang dengan permainan kartu ini..?'

SL : 'senang kak ...'

T : 'terima kasih dik...'

Berdasarkan penggalan dua wawancara tersebut dapat dilihat bahwa siswa tertarik dengan permainan kartu pecahan senilai. Siswa merasa senang karena kegiatan dikemas dalam permainan. Siswa Perempuan (SP) sempat mengalami kebingungan diawal permainan ini, tetapi setelah mendapatkan penjelasan siswa perempuan (SP) dapat mengikuti permainan kartu ini, sedangkan Siswa Laki-laki (SL) tidak mengalami kesulitan dalam permainan ini. Hal ini dikarenakan kemampuan konsep perkalian yang berbeda dari masing - masing siswa.

Evaluasi kegiatan juga dilakukan dengan mitra yaitu pihak pengelola bimbel. Berikuta adalah kutipan evaluasi yang diberikan pengelola bimbel "Saya sangat mengapresiasi kegiatan PKM ini. Media yang diguakan juga menarik karena dilakukan dengan permainan. Dengan permainan, siswa akan tertarik dalam belajar. Harapan saya kegiatan seperti ini bisa dilaksanakan kembali di tempat kami."

Adapun manfaat dari kartu perkalian senilai ini adalah : (a) meningkatkan kemampuan perkalian pada siswa Sekolah Dasar (SD) melalui media pembelajaran, (b) memberikan referensi bagi guru (tutor) maupun sekolah terkait media pembelajaran inovatif untuk diaplikasikan di dalam proses pembelajaran, (c) meminimalisir penggunaan permainan yang kurang bermanfaat dan negatif (gadget). (d) menciptakan permainan edukatif yang menyenangkan. Sementara itu menurut (Suryana, 2018), media adalah alat 
bantu atau pelengkap yang digunakan dalam berkomunikasi dengan siswa. Media mempunyai peranan yang sangat penting dalam proses pembelajaran, yaitu membantu proses pembelajaran lebih produktif. Media dalam pembelajaran dapat membangkitkan keinginan dan minat baru, meningkatkan motivasi dan rangsangan kegiatan belajar, dan bahkan berpengaruh secara psikologis kepada peserta didik. Jadi, media berfungsi untuk meningkatkan proses belajar siswa mulai dari minat dan motivasi belajar (Purnama, 2017).

Selain itu media dengan permainan akan memberikan kesenangan kepada peserta didik dalam pembelajaran. Hal ini sesuai dengan yang disampaikan Hernowo dalam (Maspalah, 2013), yang menyatakan bahwa kesenangan yang dirasakan siswa dalam belajar akan berpengaruh terhadap hasil belajarnya. Belajar akan sangat efektif jika berlangsung dalam suasana yang menyenangkan. Berdasarkan pendapat - pendapat tersebut, maka dapat disimpulkan bahwa salah satu alternatif atau cara agar pembelajaran matematika terasa menyenangkan, tidak monoton dan tidak membosankan adalah dengan memanfaatkan media pembelajaran yang membuat siswa lebih antusias dalam belajar.

Menurut (Sulistyowati, 2014), penggunaan permainan dalam pembelajaran, diharapkan siswa akan memiliki sikap positif terhadap matematika yang lebih baik, dapat belajar mandiri, dan melatih kerja sama. Hal ini sesuai dengan hasil wawancara yang dilakukan oleh tim PKM dengan siswa yang merasa senang dengan permainan kartu ini sehingga lebih bersemangat dalam belajar materi perkalian. Selain itu menurut (Andrijati, 2014) media pembelajaran matematika memiliki peranan sangat besar bagi guru yaitu untuk menyampaikan konsep-konsep dasar matematika. Hal ini sesuai dengan manfaat permainan kartu perkalian senilai pada kegiatan ini yaitu memberikan referensi bagi guru (tutor) maupun sekolah terkait media pembelajaran inovatif untuk diaplikasikan di dalam proses pembelajaran.

\section{Luaran Yang Dicapai}

Adapun Luaran yang dicapai dalam kegiatan Pengabdian Kepada Masyarakat (PKM) ini adalah :

1. Guru / Tutor di Bimbingan belajar dapat menerapkan pembelajaran dengan metode permainan kartu ini untuk memantapkan konsep perkalian siswa.

2. Guru/ Tutor dapat mengembangkan permainan katru ini untuk materi - materi yang lain.

3. Siswa tidak lagi menganggap pelajaran matematika adalah pelajran yang menakutkan karena pembelajaran matematika dapat dilakukan dengan permainan.

4. Luaran yang berupa artikel dalam kegiatan ini akan dipublikasikan pada Jurnal Pengabdian kepada Masyarakat (PkM) Universitas Indraprasta PGRI.

Berikut adalah foto - foto kegiatan Pengabdian Kepada Masyarakat (PKM) yang telah dilaksanakan. 


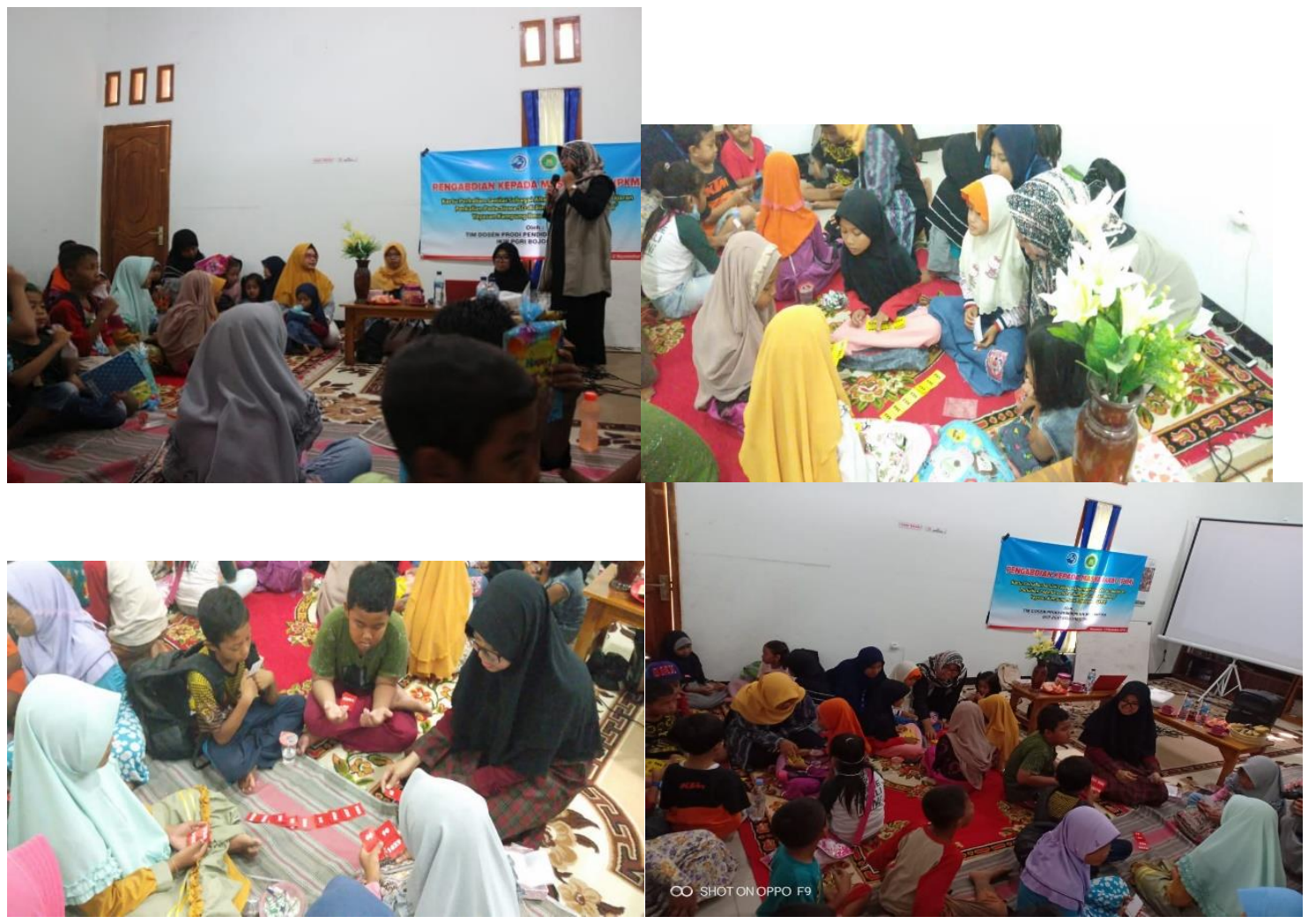

\section{SIMPULAN}

Berdasarkan pelaksanaan kegiatan PKM (Pengabdian Kepada Masyarakat) dapat diuraikan beberapa kesimpulan sebagai berikut :

1. Kegiatan PKM (Pengabdian Kepada Masyarakat) berjalan lancar sesuai dengan apa yang diharapkan dan mendapatkan apresiasi dari pihak mitra yaitu Bimbel "Gugusan Bintang" Yayasan Kampung Ilmu Bojonegoro (YKIB).

2. Kegiatan PKM (Pengabdian Kepada Masyarakat) ini memberikan manfaat bagi siswa bimbel dan guru (tutor), karena sebelumnya belum ada kegiatan seperti ini, khususnya permainan untuk pembelajaran matematika, sehingga siswa lebih tertarik dan semangat dalam belajar.

3. Kegiatan PKM (Pengabdian Kepada Masyarakat) ini perlu diagendakan secara kembali serta untuk membangun link (jaringan) dan kerjasama yang baik antara pihak kampus dengan mitra.

\section{DAFTAR PUSTAKA}

Andrijati, N. (2014). Penerapan Media Pembelajaran Inovatif dalam Pembelajaran Matematika Sekolah Dasar di PGSD UPP Tegal. Jurnal Penelitian Pendidikan, 31(2)., 123-132. https://doi.org/10.15294/jpp.v31i2.5696 
Anugraheni, I. (2017). Analisa Faktor-Faktor yang Mempengaruhi Proses Belajar GuruGuru Sekolah Dasar. Kelola: Jurnal Manajemen Pendidikan, 4(2), 205-212. https://doi.org/10.24246/j.jk.2017.v4.i2.p205-212

Maspalah. (2013). Maspalah, M. Penggunaan Permainan Memasangkan Kartu Dalam Pembelajaran Bahasa Arab Di SMA. Jurnal Pendidikan Bahasa dan Sastra, 13(1), 51-61. https://doi.org/10.17509/bs_jpbsp.v13i1.760

Nurdin, A. (2017). Pendidikan Life Skill Dalam Menumbuhkan Kewirausahaan Pada Peserta Didik Pendidikan Nonformal Paket C. Tarbawi: Jurnal Keilmuan Manajemen Pendidikan, 2(02), 109-118.

Purnama, M. D., Irawan, E. B., \& Sadijah, C. (2017). Pengembangan media box mengenal bilangan dan operasinya bagi siswa kelas 1 di SDN Gadang 1 Kota Malang. Jurnal Kajian Pembelajaran Matematika, 1(1), $46-51$. http://journal2.um.ac.id/index.php/jkpm/article/view/587

Rohmah, N. (2016). Bermain dan pemanfaatannya dalam perkembangan anak usia dini. Tarbawi: Jurnal Pendidikan Islam, 13(2). https://doi.org/10.34001/tarbawi.v13i2.590

Sulistyowati, E. (2014). Penggunaan Permainan dalam Pembelajaran Perkalian di Kelas II SD/MI. Al-Bidayah: Jurnal Pendidikan Dasar Islam,6(2)., 143-158. https://doi.org/10.14421/al-bidayah.v6i2.135

Suriyah, P., Indriani, A., Novianti, D. E., \& Rohman, N. (2018). Media Pembelajaran Inovatif House Of Multiplication Bagi Siswa Sdn Sidorejo Sebagai Upaya Hitung Cepat Perkalian. J-ADIMAS (Jurnal Pengabdian kepada Masyarakat), 6(2), 5056. http://dx.doi.org/10.29100/j-adimas.v6i2.881

Suryana, N. M., \& Indrawati, D. (2018). Pengembangan Media Pembelajaran Berbasis Permainan Tradisional "Gaprek Kaleng” untuk Menanamkan Konsep Pecahan Siswa Kelas III SD. Jurnal Penelitian Pendidikan Guru Sekolah Dasar, 6(3)., 219-228. https://jurnalmahasiswa.unesa.ac.id/index.php/jurnal-penelitianpgsd/article/view/23503

Undang-Undang Nomor 20 tahun 2003 tentang Sistem Pendidikan nasional. Jakarta : 8 Juli 2003. 